Check for updates

Cite this: RSC Adv., 2018, 8, 40748

\title{
Simultaneous optimization of ultrasonic-assisted extraction of antioxidant and anticoagulation activities of compounds from Leonurus japonicus Houtt. by response surface methodology $\dagger$
}

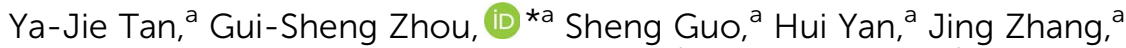 \\ Zhen-Hua Zhu, ${ }^{a}$ Xu-Qin Shi, ${ }^{a}$ Shi-Jun Yue, ${ }^{b}$ Yu-Ping Tang, ${ }^{\text {*ab }}$ Sheng-Liang Huang, \\ Guo-Ping Peng ${ }^{a}$ and Jin-Ao Duan (D) ${ }^{a}$
}

\begin{abstract}
Leonurus japonicus Houtt. is a herbaceous annual of the Lamiaceae family with pantropical distribution; it is called motherwort in China. It plays important roles in anticoagulation and antioxidation. This study aimed to explore the optimization of ultrasound-assisted extraction of multiple compounds from motherwort as well as their antioxidant and anticoagulation activities using response surface methodology. Box-Behnken design was employed to optimize three significant influences, namely extraction time, extraction temperature and ethanol concentration. The optimum extraction parameters acquired based on a combination of the yield of the target compounds and their antioxidant and anticoagulation activities were an extraction time of $38.2 \mathrm{~min}$, an extraction temperature of $30.0^{\circ} \mathrm{C}$, an ethanol concentration of $48.9 \%(\mathrm{v} / \mathrm{v})$, a solid-liquid ratio of $30.0 \mathrm{~mL} \mathrm{~g}^{-1}$ and an ultrasonic power of $500.0 \mathrm{~W}$. Under the optimal conditions, the maximal yield of the anticoagulation and antioxidant compounds of motherwort was $0.994 \%$; the thrombin time was $19.872 \mathrm{~s}$; prothrombin time was $8.270 \mathrm{~s}$; the activated partial thromboplastin time was $15.535 \mathrm{~s}$; the fibrinogen was $1.420 \mathrm{~g} \mathrm{~L}^{-1}$; and the 1,1-diphenyl-2-picrylhydrazyl free radical scavenging activity was $1.503 \mathrm{mg} \mathrm{mL}^{-1}$. The optimized conditions model showed a good correlation between the predicted and experimental values. According to the results of our study, the optimization extraction significantly enabled study of the anticoagulation and antioxidant activities of compounds in motherwort; this may contribute to future research on the pharmacological activities of motherwort.
\end{abstract}

Received 4th September 2018 Accepted 16th November 2018

DOI: $10.1039 / c 8 r a 07361 a$

rsc.li/rsc-advances

\section{Introduction}

Leonurus japonicus Houtt. (LJ), a traditional herb with a long history of medicinal use, is found in several regions in Asia, including China, Korea and Japan. China is the main productive area of LJ. ${ }^{1}$ In China, LJ is an abundant resource, and the production of LJ is nearly hundreds of thousands of tons. ${ }^{2}$

ajiangsu Collaborative Innovation Center of Chinese Medicinal Resources Industrialization, Jiangsu Key Laboratory for High Technology Research of TCM Formulae, National and Local Collaborative Engineering Center of Chinese Medicinal Resources Industrialization and Formulae Innovative Medicine, Nanjing University of Chinese Medicine, Nanjing 210023, Jiangsu Province, China. E-mail: zhouguisheng1@126.com; 2051001@sntcm.edu.cn

${ }^{b}$ Key Laboratory of Shaanxi Administration of Traditional Chinese Medicine for TCM Compatibility, Shaanxi Key Laboratory of Chinese Medicine Fundamentals and New Drugs Research, Shaanxi Collaborative Innovation Center of Chinese Medicinal Resources Industrialization, Shaanxi University of Chinese Medicine, Xi'an 712046, China

'Jiangsu Rongyu Pharmaceutical Co., Ltd., Huaian 223200, Jiangsu Province, China $\dagger$ Electronic supplementary information (ESI) available. See DOI: 10.1039/c8ra07361a
In 1990, LJ was added to the Pharmacopoeia of the People's Republic of China. According to preliminary statistics, more than 300 prescriptions containing $\mathrm{LJ}$ have been adopted to treat many diseases, especially those interfering with blood coagulation, in China. Some well-known prescriptions are currently widely used, such as "Xin-Sheng-Hua Granule" and "Ba Zhen Yi Mu Wan".,3-5 Currently, due to its pharmacological anti-cancer, anti-inflammatory, antibacterial, antifungal and antioxidant effects, LJ is widely used in health care products and/or functional foods to improve the symptoms of blood coagulation and oxidative damage in some common chronic diseases, such as cancer, diabetes and cardiovascular diseases.

Modern pharmacological research has indicated that excessive oxidative stress and blood coagulation are associated with cancer, diabetes and cardiovascular diseases. ${ }^{6-8}$ Furthermore, smoking, radiation and environmental pollutants may cause excessive oxidative stress and blood coagulation in the human body. Therefore, anticoagulants and antioxidants can be regarded as effectual methods to prevent and decrease the negative effects caused by blood coagulation and oxidative 
stress, respectively. ${ }^{9-11}$ Previous studies have reported that common herbs, such as Persicae Semen, Carthami Flos and Crataegi Fructus, are excellent sources of natural anticoagulants and antioxidants due to their high anticoagulation and antioxidant activities. ${ }^{12-17}$ According to social research, the use of natural anticoagulants and antioxidants in medicine, health products, cosmetics and food processing is steadily increasing; therefore, it is necessary to identify and research natural anticoagulants and antioxidants from plant sources.

As a traditional Chinese herbal medicine, previous reports and our preliminary experiments simultaneously proved that LJ possesses both high antioxidant and remarkable anticoagulation activities. ${ }^{1,2}$ However, to date, there have been few studies on the connection between the effects of antioxidant and anticoagulation compounds in LJ. Additionally, $\mathrm{LJ}$ is inexpensive and readily available, and it is generally considered as waste in the areas in which it is produced. In the local region, $\mathrm{LJ}$ is commonly cremated and/or abundantly discarded in soil and water; no local enterprises collect LJ practically. Moreover, due to its vast planting area and detrimental effects on the environment, $\mathrm{LJ}$ is a pressing problem for local farmers, enterprises and governments. The main reason for the waste of $\mathrm{LJ}$ is that there are few studies on its applications and adequate value-added processes. Additionally, only limited research has focused on how to transform waste $\mathrm{LJ}$ into other valuable products, which undoubtedly leads to further waste of LJ. Therefore, we believe it is imperative to find a new and environmentally friendly method to solve the above problem. An effective method would enable the preparation of the abundant antioxidants and anticoagulants in $\mathrm{LJ}$ as valuable products. This could provide a wide area for its development and utilization; this would not only reduce the pressure of waste $\mathrm{LJ}$ on abundant planting areas, but would also create more assets for local farmers and decrease environmental pollution.

To isolate natural bioactive compounds from plants, extraction is the first key step. According to previous reports, conventional solvent and Soxhlet methods are commonly used for the extraction of antioxidant and anticoagulant compounds from plants; these methods possess many shortcomings, such as high usage of extraction solvents, long extraction times, inconvenient operation and poor extraction efficiency. ${ }^{18}$ Currently, increasing numbers of extraction methods, including ultrasound-assisted extraction (UAE), ${ }^{19-21}$ microwave-assisted extraction (MAE), ${ }^{22}$ pressurized liquid extraction, ${ }^{23}$ and supercritical fluid extraction, are being developed for the recovery of antioxidant and anticoagulation compounds from plants. ${ }^{24}$ Comparatively speaking, MAE and UAE are better than other traditional extraction methods; they can decrease the extraction time and the usage of solvents, optimize the extraction temperature and increase the yields of target compounds. ${ }^{25-28}$ Particularly, UAE can disrupt cellular walls, allowing better penetration of solvents in the matrix material; this improves mass transfer and increases the release of cell contents. ${ }^{29}$ Moreover, UAE is the simplest and most economical technique, and it can be readily scaled up for industrial production. Many factors, including ultrasound power, extraction time and temperature, and solvent-tomaterial ratio, can influence the UAE process individually and collectively; thus, it is difficult to identify main independent variables to optimise. . $^{30,31}$ From previous reports, conventional multivariable optimisation is usually based on single-factor experiments and orthogonal experimental design; this method possesses many disadvantages, such as high cost, more experiments and inaccurate results. ${ }^{32}$ Response surface methodology (RSM) is a useful tool for evaluating multiple parameters; it can effectively overcome the drawbacks of single-factor experiments and orthogonal experimental design. RSM has been successfully used to optimize the extraction of active compounds from plants, such as polyphenols, polysaccharides and proteins..$^{32-35}$

Additionally, it is recognized that the simultaneous analysis of acidic and alkaline components is difficult in plant matrices because they can undergo acid-base neutralization reactions. ${ }^{36}$ LJ contains a variety of alkaloids, flavones, diterpenes and phenolic acids; ${ }^{1}$ thus, both acidic and alkaline components are present in extracts of LJ. Previous studies showed that high performance liquid chromatography (HPLC) and ultraperformance liquid chromatography tandem massspectrometry (UPLC-MS/MS) can be used to analyze the different components of LJ; however, these studies only focused on the determination of alkaline (alkaloids) or acidic (flavones and phenolic acids) components, and there are few studies on the simultaneous determination of alkaline and acidic components in LJ. ${ }^{37-39}$ To solve the problem of the coexistence of acid and alkaline compounds, in this paper, we developed a method involving ultra-performance liquid chromatography coupled with triple-quadrupole tandem mass spectrometry (UPLC-TQMS/MS) for simultaneous determination of alkaline and acidic components in LJ.

Thus, the present study was designed to determine the optimum UAE conditions for maximizing the yields and antioxidant and anticoagulation activities of compounds from LJ. As far as we know, there are no relevant reports on the application of RSM to the optimization of UAE conditions for obtaining remarkable antioxidant and anticoagulation activities of compounds in LJ. Additionally, this is the first time that a rapid and accurate quality control UPLC-TQ-MS/MS method was employed to simultaneously analyze acid and alkaline compounds in LJ.

\section{Materials and methods}

\subsection{Herbal samples}

The samples of Leonurus japonicus Houtt. (LJ) were collected in August 2017 from fields in Xuyi County, Jiangsu Province, China. The plant was authenticated by Dr Hui Yan (Department of Medicinal Plants, Nanjing University of Chinese Medicine, Nanjing, China). A voucher specimen (NJUCM-20170830) was deposited in the Herbarium of Nanjing University of Chinese Medicine. 
Table 1 MS parameters of the 20 investigated target compounds

\begin{tabular}{|c|c|c|c|c|c|c|}
\hline Compound & MW & MRM transition & Cone voltage (V) & Collision energy (eV) & $R_{\mathrm{t}}(\min )$ & Ion mode \\
\hline 1 & 137.14 & $138.10>91.66$ & 30 & 22 & 2.92 & $\mathrm{ES}+$ \\
\hline 2 & 179.50 & $144.07>84.10$ & 36 & 22 & 2.99 & $\mathrm{ES}+$ \\
\hline 3 & 354.31 & $353.22>191.07$ & 18 & 18 & 6.19 & $\mathrm{ES}-$ \\
\hline 4 & 347.79 & $312.14>181.04$ & 26 & 24 & 6.94 & $\mathrm{ES}+$ \\
\hline 5 & 610.51 & $609.16>300.16$ & 40 & 32 & 7.00 & $\mathrm{ES}-$ \\
\hline 6 & 138.13 & $139.00>95.01$ & 28 & 12 & 7.00 & ES+ \\
\hline 7 & 198.18 & $199.04>140.01$ & 12 & 14 & 7.04 & $\mathrm{ES}+$ \\
\hline 8 & 180.15 & $181.10>163.06$ & 12 & 10 & 7.06 & ES+ \\
\hline 9 & 168.15 & $169.00>64.99$ & 24 & 12 & 7.14 & $\mathrm{ES}+$ \\
\hline 10 & 594.52 & $593.22>284.82$ & 40 & 28 & 7.33 & $\mathrm{ES}-$ \\
\hline 11 & 464.38 & $465.22>303.18$ & 12 & 22 & 7.37 & $\mathrm{ES}+$ \\
\hline 12 & 464.38 & $463.15>301.09$ & 14 & 12 & 7.41 & ES+ \\
\hline 13 & 194.19 & $195.03>144.87$ & 14 & 18 & 8.14 & ES+ \\
\hline 14 & 122.12 & $123.00>78.99$ & 24 & 8 & 9.30 & $\mathrm{ES}+$ \\
\hline 15 & 302.00 & $301.03>151.00$ & 30 & 20 & 9.54 & $\mathrm{ES}-$ \\
\hline 16 & 270.24 & $271.10>152.96$ & 62 & 30 & 10.18 & $\mathrm{ES}+$ \\
\hline 17 & 286.23 & $287.10>153.01$ & 44 & 28 & 10.39 & $\mathrm{ES}+$ \\
\hline 18 & 316.26 & $315.16>299.99$ & 38 & 22 & 10.44 & $\mathrm{ES}-$ \\
\hline 19 & 284.27 & $285.10>270.07$ & 32 & 24 & 12.24 & ES+ \\
\hline 20 & 284.27 & $285.08>242.02$ & 56 & 30 & 12.47 & $\mathrm{ES}+$ \\
\hline
\end{tabular}

\subsection{Chemicals and solvents}

All chemicals and reagents were of HPLC grade. The standard of 1,1-diphenyl-2-picrylhydrazyl (DPPH) was purchased from Nanjing Jiancheng Bioengineering Institute (Nanjing, China). Activated partial thromboplastin time (APTT), prothrombin time (PT), thrombin time (TT) and fibrinogen (FIB) assay kits were purchased from Nanjing Maibo Biotech Co. Ltd (Nanjing, China). Other standards of trigonelline (1), stachydrine hydrochloride (2), chlorogenic acid (3), leonurine hydrochloride (4), rutin (5), $p$-hydroxybenzoic acid (6), syringic acid (7), caffeic acid (8), vanillic acid (9), kaempferol-3-O-rutinoside (10), hyperoside (11), isoquercitrin (12), ferulic acid (13), benzoic acid (14), quercetin (15), apigenin (16), kaempferol (17), isorhamnetin (18), wogonin (19) and genkwanin (20) were purchased from Nanjing Liangwei Biotech Co. Ltd (Nanjing, China). The purity of each compound was $>98 \%$. Deionized water was purified by a Milli-Q water purification system from Millipore (MA, USA). Other reagents such as formic acid, acetonitrile and anhydrous ethanol were supplied by Merck (Darmstadt, Germany).

\subsection{Determination of extraction yield}

The extraction yield of $\mathrm{LJ}$ was represented by the total contents of the main components, including alkaloids (1, 2 and 4 ), flavonoids $(5,11,12,15,16,17,18,19$ and 20), phenolic acids (3, 6, 7, 8, 9, 13 and 14) and glycosides (10). These components, the main active compounds in LJ, were identified and determined by UPLC-TQ-MS. UPLC was performed on a Waters Acquity UHPLC system (Waters, Milford, MA, USA) equipped with a quaternary pump solvent management system, an online degasser, a triple quadrupole mass detector and an autosampler. An Acquity UPLC BEH $\mathrm{C}_{18}$ column $(2.1 \mathrm{~mm} \times 100 \mathrm{~mm}, 1.7$ $\mu \mathrm{m})$ was used with an injection volume of $2 \mu \mathrm{L}$. The column temperature was maintained at $35^{\circ} \mathrm{C}$. The mobile phase was composed of A ( $0.1 \%$ formic acid solution) and B (acetonitrile

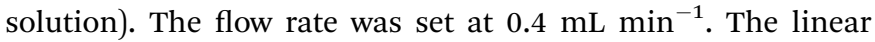
gradient conditions were: $90 \% \mathrm{~A}$ (0 to $1.0 \mathrm{~min}$ ), $90 \%$ to $50 \% \mathrm{~A}$ (1.0 to $7.0 \mathrm{~min}$ ), $50 \%$ to $10 \% \mathrm{~A}(7.0$ to $13.0 \mathrm{~min}), 10 \%$ to $0 \% \mathrm{~A}$ (13.0 to $14.0 \mathrm{~min}$ ) and $0 \%$ A (14.0 to $14.5 \mathrm{~min})$. A Waters Synapt mass spectrometer (Waters) was used for the mass spectrometry analysis; it was equipped with an electrospray ionization source (ESI) in both positive and negative modes with a scan range of $\mathrm{m} / z 100$ to $1000 \mathrm{Da}$. The MS parameters are listed in Table 1. Representative MRM chromatograms for the $50 \mathrm{ng} \mathrm{mL}^{-1}$ mixture of the 20 standard analytes and sample are shown in Fig. 1a and b, respectively. Also, the chemical structures of the 20 standards are shown in Fig. 2.

In this part, 20 standards were used to identify multiple compounds from LJ, and the contents of the 20 components are displayed as the dry weight of LJ. The extraction yield of LJ was calculated by the following formula:

$$
\text { Extraction yield } \begin{aligned}
(\%) & =\text { alkaloids }(\%)+\text { flavonoids }(\%) \\
& + \text { phenolic acids }(\%)+\text { glycoside }(\%)
\end{aligned}
$$

\subsection{Ultrasound-assisted extraction procedure}

In this study, UAE was applied for the extraction of multiple components from LJ. An ultrasonic device (KH-500 DB; Kunshan Hechuang Ultrasonic Instrument Factory, Kunshan, China) was used for UAE; this device can be used to adjust and control the sonication power, time and temperature simultaneously. The samples of LJ were cut into segments and crushed into powder, which was filtered through a no. $3(355 \mu \mathrm{m} \pm 13$ $\mu \mathrm{m})$ sieve. Then, the powdered sample $(0.5 \mathrm{~g})$ was mixed with ethanol solution in a conical flask. All the samples were extracted in triplicate simultaneously. After UAE, the extracting 

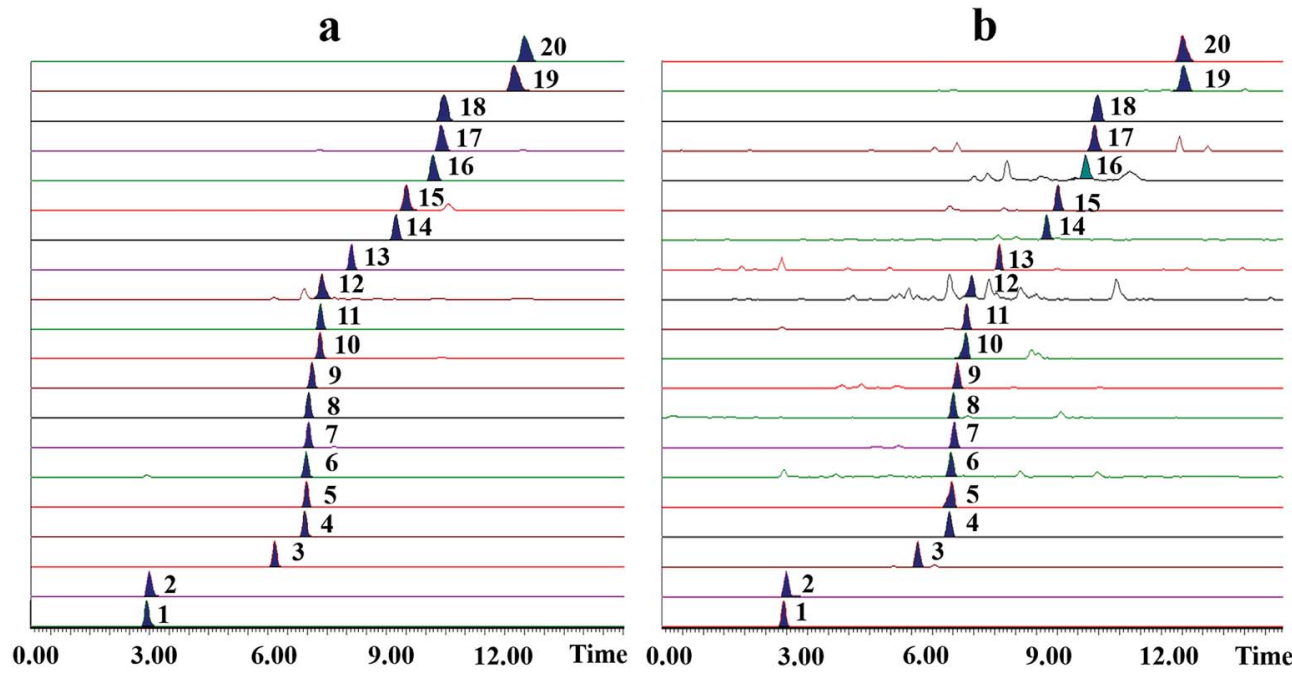

Fig. 1 Representative MRM chromatogram of 20 compounds in $50.0 \mathrm{ng} \mathrm{mL}^{-1}$ mixture standards (a) and a sample (b). Peaks: 1 (trigonelline), 2 (stachydrine hydrochloride), 3 (chlorogenic acid), 4 (leonurine hydrochloride), 5 (rutin), 6 ( $p$-hydroxybenzoic acid), 7 (syringic acid), 8 (caffeic acid), 9 (vanillic acid), 10 (kaempferol 3-O-rutinoside), 11 (hyperoside), 12 (isoquercitrin), 13 (ferulic acid), 14 (benzoic acid), 15 (quercetin), 16 (apigenin), 17 (kaempferol), 18 (isorhamnetin), 19 (wogonin) and 20 (genkwanin).

solution was centrifuged and the supernatant was collected for the subsequent experiments, including UPLC-TQ-MS/MS analysis and the determination of the antioxidant and anticoagulation activities.

\subsection{Experimental design}

The experiments were executed in three phases. (1) The effects of three solvents, namely water, methanol and ethanol, on the yield of compounds with antioxidant and anticoagulation activities in LJ were compared. (2) Ethanol was chosen as the extraction solvent in the first phase, and the following parameters were investigated: ethanol concentration ( $10 \%$ to $90 \%)$, solid-liquid ratio $\left(10: 1\right.$ to $\left.80: 1 \mathrm{~mL} \mathrm{~g}^{-1}\right)$, temperature $\left(30^{\circ} \mathrm{C}\right.$ to $\left.70^{\circ} \mathrm{C}\right)$, ultrasonic power $(200$ to $500 \mathrm{~W})$ and ultrasonication time (10 to $90 \mathrm{~min}$ ). (3) The variables of significance determined from the single-factor experiment were investigated by RSM with Box-Behnken design (BBD). The independent variables (Table 2) were selected based on previous reports. ${ }^{40,46}$ Also, the 17 BBD design experiments are displayed in Table 3.

\subsection{Determination of anticoagulation activity}

The anticoagulation activity of $\mathrm{LJ}$ was evaluated by activating the TT, PT, APTT and FIB assays in vitro. In this study, blood samples were collected from rabbit auricular vein (no: 2017-021) and deposited into a $10 \mathrm{~mL}$ centrifuge tube, where they were soaked in sodium citrate $\left(38 \mathrm{mg} \mathrm{mL}^{-1}, 800 \mu \mathrm{L}\right)$. Then, the above blood samples were centrifuged at $3000 \mathrm{rpm}\left(4{ }^{\circ} \mathrm{C}\right)$ for $15 \mathrm{~min}$ and the plasma was acquired for the next experiments. All the animal procedures and experiments were approved by the Animal Ethical Committee of Nanjing University of Chinese Medicine, (Nanjing, China). All experiments were performed according to the guidelines of the National Institute of Health and the institutional rules for the use and care of laboratory animals at Nanjing University of Chinese Medicine (Nanjing, China).

2.6.1. TT assay. TT is mainly reflected by the time of conversion from fibrinogen to fibrin. An increase in TT indicates that the sample has invigorating effects on blood circulation. The specific operation was as follows: $50 \mu \mathrm{L}$ of $\mathrm{LJ}$ extract and $200 \mu \mathrm{L}$ of plasma were added to the test cup, respectively; then, the mixture was incubated at $37^{\circ} \mathrm{C}$ for $3 \mathrm{~min}$. Finally, 200 $\mu \mathrm{L}$ TT reagent were added, and the clotting time (TT value) was recorded. ${ }^{41}$

2.6.2. PT assay. PT mainly indicates the status of the extrinsic blood coagulation system. When a sample has an invigorating effect on blood circulation, PT will increase. In contrast, PT decreases if the sample causes blood coagulation. In this assay, $25 \mu \mathrm{L}$ of $\mathrm{LJ}$ extract was added to the test cup, followed by $100 \mu \mathrm{L}$ of plasma. Similarly, the mixture was maintained at $37{ }^{\circ} \mathrm{C}$ for $3 \mathrm{~min}$; then, $200 \mu \mathrm{L}$ PT reagent preheated to $37^{\circ} \mathrm{C}$ was added to the test cup, and the coagulation time (PT value) was then recorded. ${ }^{41}$

2.6.3. APTT assay. APTT mainly indicates the status of the intrinsic blood coagulation system. Like PT, APTT increases when a sample invigorates blood circulation. The specific operation of APTT was as follows: $100 \mu \mathrm{L}$ of plasma, $25 \mu \mathrm{L}$ of $\mathrm{LJ}$ extract and $100 \mu \mathrm{L}$ of APTT reagent preheated to $37^{\circ} \mathrm{C}$ were added in sequence to the test cup. Then, the above mixture was incubated at $37^{\circ} \mathrm{C}$ for $3 \mathrm{~min}$. In the last step, $100 \mu \mathrm{L}$ of $\mathrm{CaCl}_{2}$ solution preheated to $37{ }^{\circ} \mathrm{C}$ was added, and the coagulation time (APTT value) was recorded. ${ }^{41}$

2.6.4. FIB assay. The FIB assay demonstrates the content of fibrinogen. FIB has a normal range of 2 to $4 \mathrm{~g} \mathrm{~L} \mathrm{~L}^{-1}$, and its content decreases when the sample plays an invigorating role in the blood circulation. Firstly, we drew a standard curve according to the specified requirements; then, sample determination was performed. $100 \mu \mathrm{L}$ of $\mathrm{LJ}$ extract, $200 \mu \mathrm{L}$ of plasma 


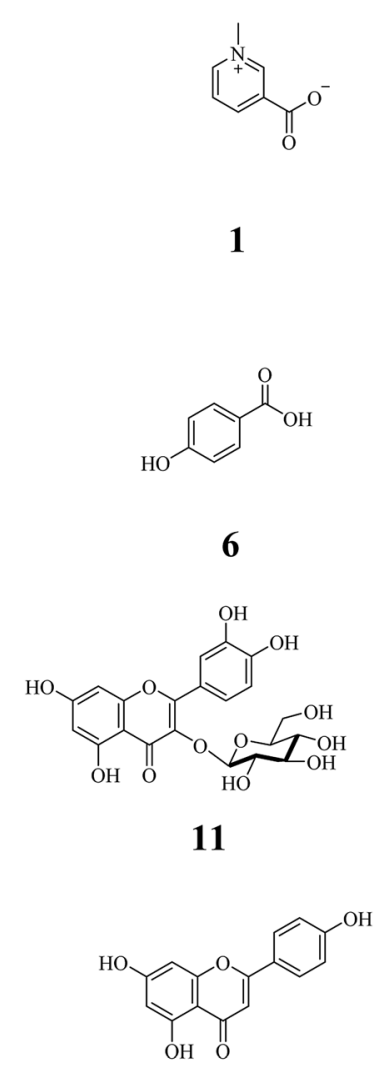

16

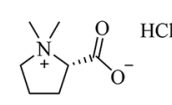

2<smiles>COc1cc(C=O)cc(OC)c1O</smiles>

7<smiles>O=c1c(OCCO)c(-c2ccc(O)c(O)c2)oc2cc(O)cc(O)c12</smiles>

12

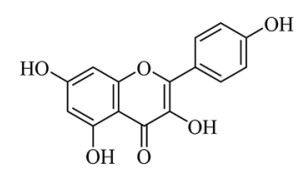

17<smiles>COc1cc(C(=O)OCCCCl)cc(OC)c1O</smiles>

4



5<smiles></smiles>

10<smiles>O=c1c(O)c(-c2ccc(O)c(O)c2)oc2cc(O)cc(O)c12</smiles>

15<smiles>COc1cc(O)c2c(=O)cc(-c3ccc(O)cc3)oc2c1</smiles>

20

Fig. 2 Chemical structures of the 20 standards in Leonurus japonicus Houtt.

Table 2 Independent variables and levels used for the Box-Behnken design

\begin{tabular}{llll}
\hline $\begin{array}{l}\text { Name, } \\
\text { unit }\end{array}$ & $\begin{array}{l}X_{1}: \\
\text { time }(\min )\end{array}$ & $\begin{array}{l}X_{2}: \\
\text { temperature }\left({ }^{\circ} \mathrm{C}\right)\end{array}$ & $\begin{array}{l}X_{3} \text { : ethanol } \\
\text { concentration }(\%(\mathrm{v} / \mathrm{v}))\end{array}$ \\
\hline Low & 20 & 30 & 20 \\
High & 50 & 70 & 70
\end{tabular}

and $700 \mu \mathrm{L}$ of buffer were blended in a tube; then, $200 \mu \mathrm{L}$ of the mixture was removed and incubated at $37^{\circ} \mathrm{C}$ for $3 \mathrm{~min}$. Finally, $100 \mu \mathrm{L}$ thrombin solution was added to the above mixture and the fibrinogen content was recorded; this content is the FIB value. ${ }^{41}$

For all the tests mentioned above, plasma and breviscapine were used as the blank control and positive control, respectively. The TT, PT, APTT and FIB assays were conducted using a semi-automatic coagulation analyzer.

\subsection{Determination of DPPH free radical scavenging activity}

To measure the antioxidant activities of the LJ extracts, we adopted the DPPH radical scavenging assay from a previous study with minor alterations. ${ }^{\mathbf{4 2 - 4 5}}$ In brief, DPPH solution was formulated by dissolving DPPH in absolute ethanol at a concentration of $0.1 \mathrm{mM}$. Then, $100 \mu \mathrm{L} \mathrm{DPPH}$ working solution were added to $100 \mu \mathrm{L}$ of $\mathrm{LJ}$ extracts with various concentrations. Then, each mixture was shaken and incubated for $30 \mathrm{~min}$ at room temperature in the dark. The absorbance of each solution was measured on a microplate reader at $517 \mathrm{~nm}$. Necessarily, ascorbic acid $\left(V_{c}\right)$ was used as a positive control. The radical scavenging activity was indicated by the percentage of DPPH according to the following formula:

$$
\mathrm{DPPH}^{2} \%=\left[1-\frac{\left(A_{1}-A_{1}^{\prime}\right)}{\left(A_{0}-A_{0}^{\prime}\right)}\right] \times 100
$$

where $A_{1}$ is the absorbance of the sample (containing DPPH solution), $A_{0}$ is the absorbance of the control (DPPH solution with no sample), $A_{1}^{\prime}$ is the absorbance of the solvent (ethanol solution with sample), and $A_{0}^{\prime}$ is the absorbance of the solvent control (ethanol solution with no sample). All the experiments were performed in triplicate and the average values were calculated. The antiradical DPPH activity was shown as $\mathrm{IC}_{50}(\mathrm{mg}$ $\mathrm{mL}^{-1}$ ), which is the concentration of sample required to scavenge $50 \%$ of DPPH free radicals.

\subsection{Data analysis}

All the experiments were performed in triplicate, and Design Expert software version 8.0 (Stat-Ease Inc., Minneapolis, USA) 
Table 3 Response surface design and experimental results

\begin{tabular}{|c|c|c|c|c|c|c|c|c|c|}
\hline Run & $X_{1}(\min )$ & $X_{2}\left({ }^{\circ} \mathrm{C}\right)$ & $X_{3}(\%)$ & $Y_{1}(\%)$ & $Y_{2}(\mathrm{~s})$ & $Y_{3}(\mathrm{~s})$ & $Y_{4}(\mathrm{~s})$ & $Y_{5}\left(\mathrm{~g} \mathrm{~L}^{-1}\right)$ & $Y_{6}\left(\mathrm{mg} \mathrm{mL}^{-1}\right)$ \\
\hline 1 & 35 & 50 & 45 & 0.99 & 20.58 & 8.23 & 14.25 & 1.43 & 2.98 \\
\hline 2 & 50 & 30 & 45 & 0.96 & 19.67 & 8.30 & 18.50 & 1.44 & 3.19 \\
\hline 4 & 20 & 70 & 45 & 0.84 & 20.60 & 13.68 & 17.60 & 1.45 & 2.15 \\
\hline 5 & 35 & 50 & 45 & 0.83 & 20.00 & 8.20 & 14.53 & 1.43 & 2.12 \\
\hline 6 & 50 & 70 & 45 & 0.84 & 19.40 & 6.73 & 14.33 & 1.44 & 4.89 \\
\hline 9 & 20 & 50 & 20 & 0.80 & 20.25 & 5.00 & 10.73 & 1.43 & 13.50 \\
\hline 10 & 50 & 50 & 70 & 0.80 & 19.33 & 5.57 & 17.95 & 1.43 & 7.13 \\
\hline 11 & 20 & 30 & 45 & 0.69 & 19.70 & 5.58 & 14.08 & 1.44 & 3.76 \\
\hline 12 & 35 & 50 & 45 & 0.84 & 20.27 & 6.08 & 12.63 & 1.43 & 4.46 \\
\hline 13 & 35 & 70 & 70 & 0.70 & 19.70 & 5.63 & 14.67 & 1.42 & 6.46 \\
\hline 14 & 35 & 30 & 70 & 1.26 & 19.48 & 8.15 & 14.65 & 1.42 & 6.19 \\
\hline
\end{tabular}

was used to analyse the experimental designs and data. All the results were analyzed by ANOVA, and $p$-values of less than 0.05 indicated that the data were statistically significant.

\section{Results and discussion}

\subsection{Solvent experiment analysis}

Solvents such as water, methanol and ethanol are commonly used for extraction of LJ. In this section, different solvents (water, 20\% methanol, 60\% methanol, 100\% methanol, $20 \%$ ethanol, $60 \%$ ethanol and $100 \%$ ethanol) were respectively selected to study their effects on the yield of the target compounds and the antioxidant and anticoagulation activities of different extractions from LJ. As shown in Fig. 3A-F, in accordance with all the indicators, such as the yield of the target compounds $\left(Y_{1}\right)$, ethanol performed better than methanol and water. Meanwhile, the values of TT $\left(Y_{2}\right)$, PT $\left(Y_{3}\right)$ and APTT $\left(Y_{4}\right)$ with ethanol were higher than those with methanol and water.
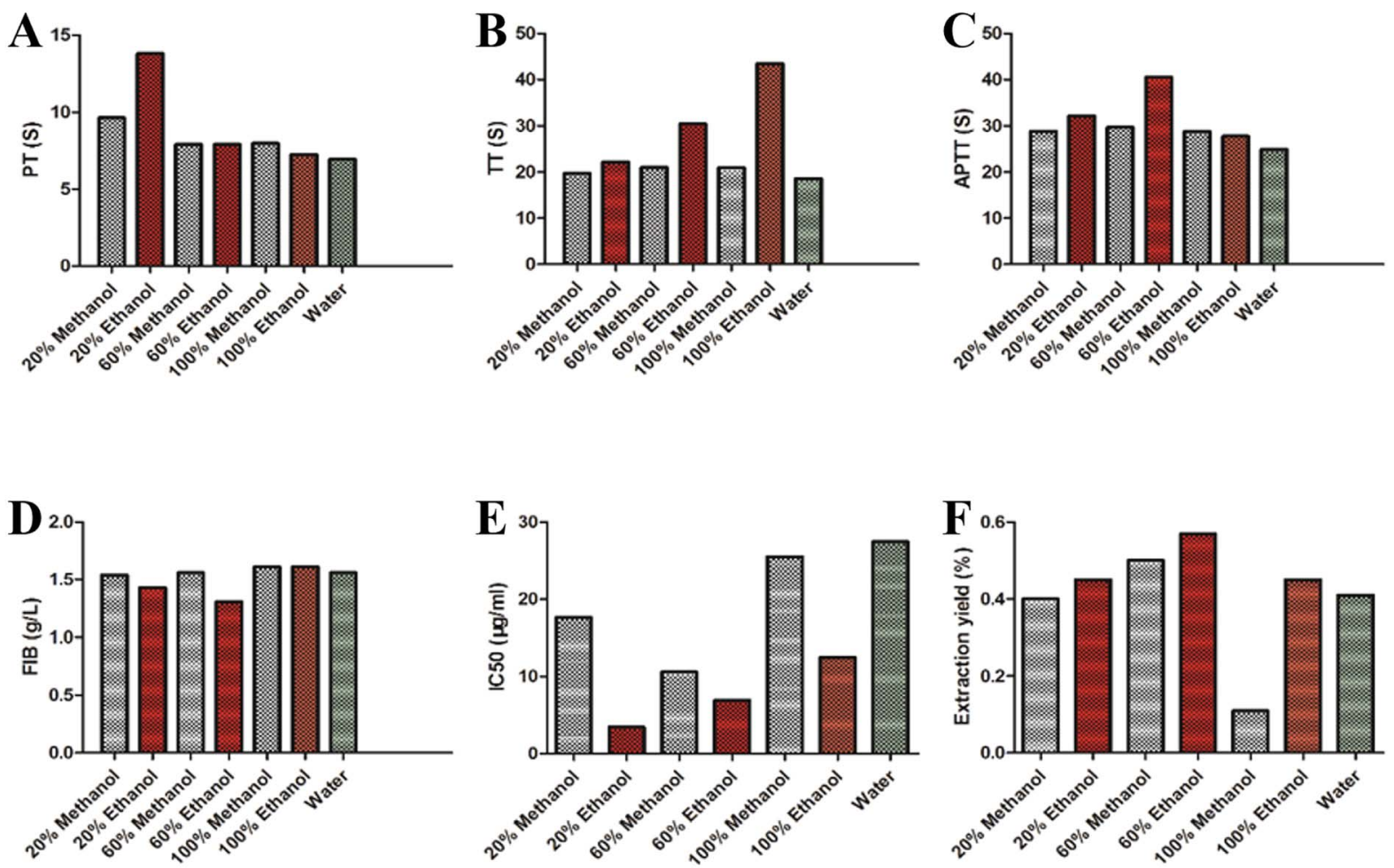

Fig. 3 Effects of different solvents (water, 20\% methanol, 60\% methanol, 100\% methanol, 20\% ethanol, $60 \%$ ethanol and $100 \%$ ethanol) on the extraction yield of $\mathrm{LJ}\left(Y_{1}\right), \mathrm{TT}\left(Y_{2}\right), \mathrm{PT}\left(Y_{3}\right), \mathrm{APTT}\left(Y_{4}\right)$, FIB $\left(Y_{5}\right)$ and DPPH free radical scavenging activity $\left(Y_{6}\right)$. 
Moreover, for the FIB $\left(Y_{5}\right)$ and DPPH free radical scavenging activity $\left(Y_{6}\right)$, the values with ethanol were lower than those with methanol and water. Therefore, ethanol was selected as the ideal solvent for the subsequent experiments. ${ }^{43}$

\subsection{Single factor experiment analysis}

3.2.1. Effects of ultrasonication time. The effects of ultrasonication time on the extraction yield of anticoagulant and antioxidant compounds from LJ were investigated at different times $(10,20,30,40,50,60,70,80$ and $90 \mathrm{~min})$ while the other extraction conditions were maintained as follows: ultrasonication temperature of $30.0{ }^{\circ} \mathrm{C}$, ethanol concentration of $70.0 \%(\mathrm{v} / \mathrm{v})$, ultrasonic power of $200.0 \mathrm{~W}$ and solid-liquid ratio of $20.0 \mathrm{~mL} \mathrm{~g}^{-1}$. As shown in Fig. 4, as the ultrasonication time increased from 10 to $50 \mathrm{~min}, Y_{1}$ was enhanced and then showed almost no changes. $Y_{2}$ to $Y_{4}$ showed continuous changes between 10 and $50 \mathrm{~min}$. Meanwhile, $Y_{5}$ decreased from 20 to $50 \mathrm{~min}$ and $Y_{6}$ decreased from 30 to $50 \mathrm{~min}$. Therefore, an ultrasonication time range of 20 to $50 \mathrm{~min}$ was chosen as optimal in the BBD experiments. ${ }^{45,46}$

3.2.2. Effects of ethanol concentration. In this part, to study the effects of ethanol concentration on the anticoagulant and antioxidant activities of LJ extracts, different ethanol concentrations of $10 \%$ to $90 \%(\mathrm{v} / \mathrm{v})$ were investigated, while the other extraction conditions were maintained as follows: ultrasonication temperature, $30.0{ }^{\circ} \mathrm{C}$; ultrasonication time, $30.0 \mathrm{~min}$; solid-liquid ratio, $20.0 \mathrm{~mL} \mathrm{~g}^{-1}$; and ultrasonic power, 200.0 W. As shown in Fig. S1, $\uparrow Y_{1}$ to $Y_{4}$ showed increasing trends as the ethanol concentration increased from $20 \%$ to $70 \%$, while $Y_{5}$ and $Y_{6}$ decreased to their valley values at ethanol concentrations of
$20 \%$ and $40 \%$, respectively. Therefore, the ethanol concentration range of $20 \%$ to $70 \%(\mathrm{v} / \mathrm{v})$ was adopted as optimal in the subsequent BBD experiments. ${ }^{45,47}$

3.2.3. Effects of solid-liquid ratio. The effects of the solidliquid ratio on the yield of the anticoagulant and antioxidant compounds of LJ were inspected at eight levels, from $10: 1$ to $80: 1 \mathrm{~mL} \mathrm{~g}^{-1}$, while the other conditions were maintained as follows: ultrasonication temperature of $30.0^{\circ} \mathrm{C}$, ultrasonication time of $30.0 \mathrm{~min}$, ethanol concentration of $70.0 \%(\mathrm{v} / \mathrm{v})$ and ultrasonic power of $200.0 \mathrm{~W}$. From Fig. S2, $\uparrow$ when the solidliquid ratios were $10: 1$ to $80: 1 \mathrm{~mL} \mathrm{~g}^{-1}, Y_{1}$ to $Y_{6}$ remained similar and showed no obvious differences. However, when the solid-liquid ratio was $30: 1 \mathrm{~mL} \mathrm{~g}^{-1}, Y_{1}, Y_{2}, Y_{4}$ and $Y_{6}$ were maximal. Thus, $30: 1 \mathrm{~mL} \mathrm{~g}^{-1}$ was chosen for the following study to optimize the extraction conditions of $\mathrm{LJ}$.

3.2.4. Effects of temperature. Temperature is an important factor that influences the extraction yield of the anticoagulant and antioxidant compounds of LJ. The effects of different temperatures $\left(30{ }^{\circ} \mathrm{C}, 40{ }^{\circ} \mathrm{C}, 50{ }^{\circ} \mathrm{C}, 60{ }^{\circ} \mathrm{C}\right.$ and $\left.70{ }^{\circ} \mathrm{C}\right)$ on the extraction efficiency of $\mathrm{LJ}$ were investigated, and the other extraction parameters were maintained as follows: ultrasonication time, $30.0 \mathrm{~min}$; ethanol concentration, $70.0 \%(\mathrm{v} / \mathrm{v})$; ultrasonic power, $200.0 \mathrm{~W}$; and solid-liquid ratio, $20.0 \mathrm{~mL}$ $\mathrm{g}^{-1}$. As shown in Fig. $\mathrm{S} 3, \dagger$ as the temperature increased from $30{ }^{\circ} \mathrm{C}$ to $50{ }^{\circ} \mathrm{C}, Y_{1}$ and $Y_{3}$ increased. After that, $Y_{1}$ and $Y_{3}$ were almost unchanged from $50{ }^{\circ} \mathrm{C}$ to $70{ }^{\circ} \mathrm{C}$. $Y_{2}$ and $Y_{4}$ showed fluctuations from $30{ }^{\circ} \mathrm{C}$ to $70{ }^{\circ} \mathrm{C}$. $Y_{5}$ and $Y_{6}$ were similar. Therefore, the temperature range of $30{ }^{\circ} \mathrm{C}$ to $70{ }^{\circ} \mathrm{C}$ was adopted as optimal in the BBD experiments.

3.2.5. Effects of ultrasonic power. The effects of ultrasonic power on the yield of the anticoagulant and antioxidant
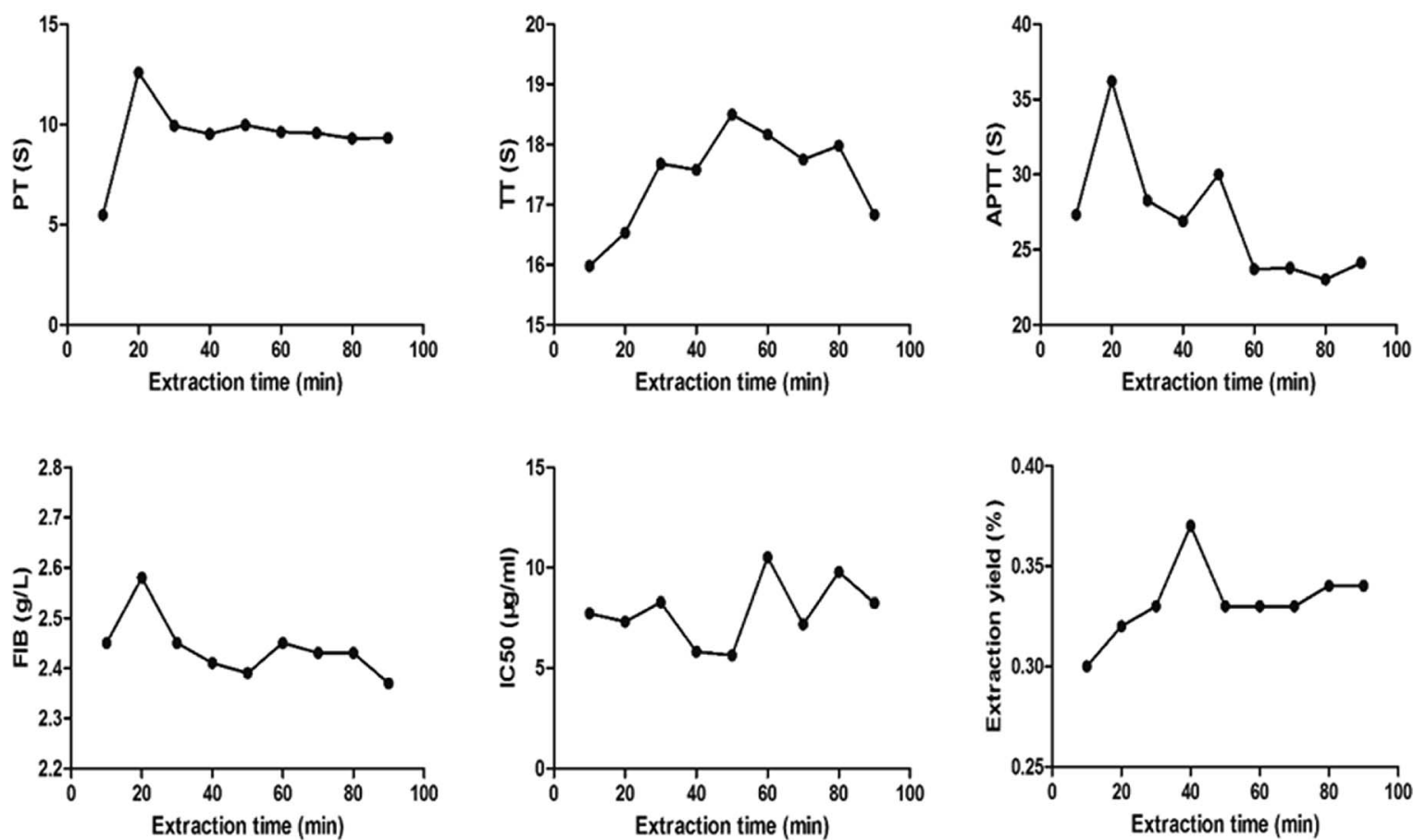

Fig. 4 Effects of ultrasonication time on the extraction yield of $L J\left(Y_{1}\right), T T\left(Y_{2}\right), \operatorname{PT}\left(Y_{3}\right)$, APTT $\left(Y_{4}\right)$, FIB $\left(Y_{5}\right)$ and DPPH free radical scavenging activity $\left(Y_{6}\right)$. 
Table 4 Analysis of variance (ANOVA) for response surface quadratic model, and fits statistics for the response values $(n=3)$

Analysis of variance (ANOVA)

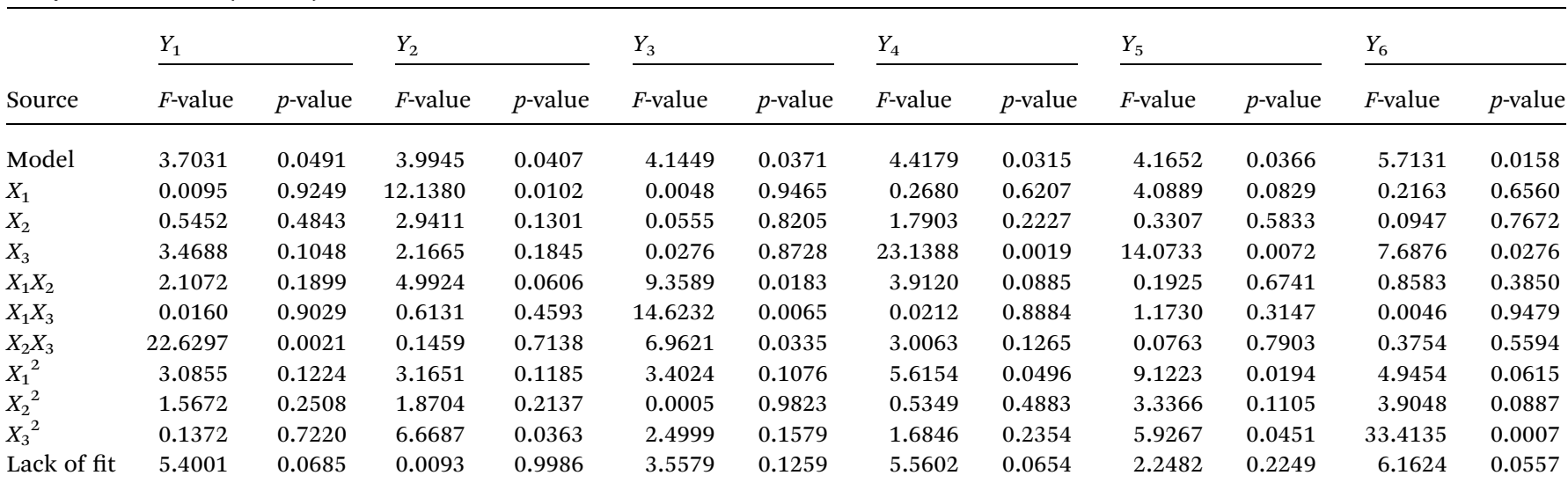

Credibility analysis of the regression equations

\begin{tabular}{lrrrrr}
\hline Index mark & $Y_{1}$ & $Y_{2}$ & $Y_{3}$ & $Y_{4}$ & $Y_{5}$ \\
\hline C.V.\% & 11.1499 & 1.3157 & 10.2907 & 13.9154 & 1.0265 \\
$R$-squared & 0.8264 & 0.8370 & 0.8420 & 0.8503 & 31.0486 \\
Adj $R$-squared & 0.6033 & 0.6275 & 0.6389 & 0.6578 & 0.8427 \\
\end{tabular}

compounds of LJ were investigated at seven levels $(200,250$, $300,350,400,450$ and $500 \mathrm{~W}$ ), while the other conditions were maintained as follows: ultrasonication temperature, $30.0{ }^{\circ} \mathrm{C}$; ultrasonication time, $30.0 \mathrm{~min}$; ethanol concentration, $70.0 \%$ $(\mathrm{v} / \mathrm{v})$; and solid-liquid ratio, $20.0 \mathrm{~mL} \mathrm{~g}^{-1}$. As can be seen in Fig. S4, $\uparrow Y_{1}$ to $Y_{6}$ were almost unchanged and had no significant differences. Thus, for convenience, the ultrasonic power of 500.0 W was chosen for further optimization experiments of the extraction conditions.

\subsection{Analysis of response surface methodology}

3.3.1. Fitting the model. Compared with traditional single parameter optimization, RSM is more efficient in that it decreases the number of experiments and saves a remarkable amount of time. A total of 17 experiments were run to optimize the three individual variables $\left(X_{1}\right.$ : extraction temperature, $X_{2}$ : extraction time and $X_{3}$ : ethanol concentration) in the current BBD, as shown in Table 3. A second order polynomial formula was adopted to correlate the independent variables with the response values of $Y_{1}$ to $Y_{6}$. A matched model for $Y_{1}$ to $Y_{6}$ was built to predict the relationships between the independent variables, and these relationships can be displayed by the following formulae:

$$
\begin{gathered}
Y_{1}=0.850-0.230 X_{2} X_{3} \\
Y_{2}=20.240-0.320 X_{1}-0.330 X_{3}^{2} \\
Y_{3}=8.020-1.170 X_{1} X_{2}-1.460 X_{1} X_{3}-1.010 X_{2} X_{3} \\
Y_{4}=13.180+3.310 X_{3}+2.25 X_{1}^{2}
\end{gathered}
$$

$$
\begin{gathered}
Y_{5}=1.430+0.019 X_{3}+0.022 X_{1}^{2}-0.017 X_{3}^{2} \\
Y_{6}=3.280-1.750 X_{3}+5.030 X_{3}^{2}
\end{gathered}
$$

The analysis of variance for the experimental results of the BBD is shown in Table 4. Taking $Y_{2}$ as an example, the $p$-value of $0.0407(p<0.05)$ indicates that the model was significant. Meanwhile, the "Lack of Fit" $p$-value of 0.9986 implied that the lack-of-fit was not significant, which further verified the validity of the model. The determination coefficient $(R)$ was 0.8370 , which indicates that the matched model can explain $83.70 \%$ of the variations. The adjusted determination coefficient ( $R$-Adj) was 0.6275 , which is close to $R$, showing that the observed values were significantly correlated with the predicted values. Furthermore, the coefficient of variation of $1.3157 \%$ indicates that the variation in the average value was low and the highaccuracy experimental results are dependable. All these results display that this model can completely explain the real relationships between the independent variables and response values. ${ }^{34,46,48,49}$

3.3.2. Effects of independent variables on the anticoagulant and antioxidant activities of $\mathrm{LJ}$ in the RSM model

3.3.2.1. Extraction yield of $L J\left(Y_{1}\right)$. To study the interactive effects of the independent variables on the extraction yield of $\mathrm{LJ}$, three-dimensional response surfaces are shown in Fig. 5A-C and contour plots are shown in Fig. 5a-c. Fig. 5A and a show the interactive effects between ethanol concentration and temperature while the ultrasonication time remains at 0-level. When the temperature was fixed, $Y_{1}$ rapidly increased with increasing ethanol concentration until it reached a maximum; then, it slowly decreased. These results indicate that most of the target components (medium-polarity compounds) from LJ can be 


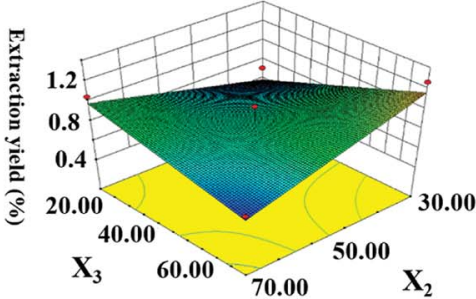

A

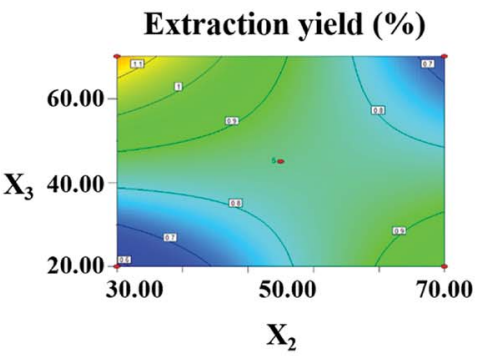

a

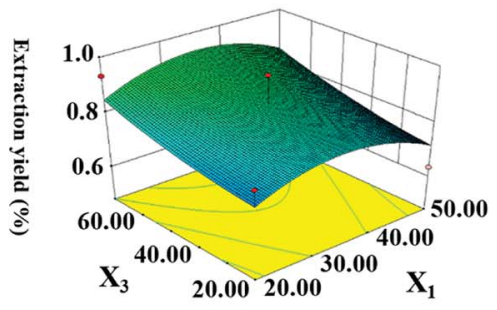

B

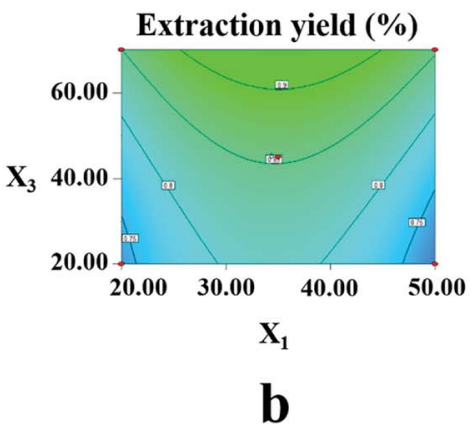

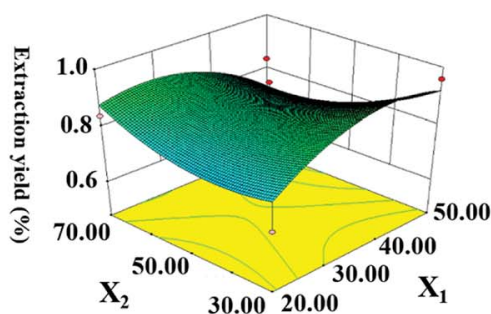

C

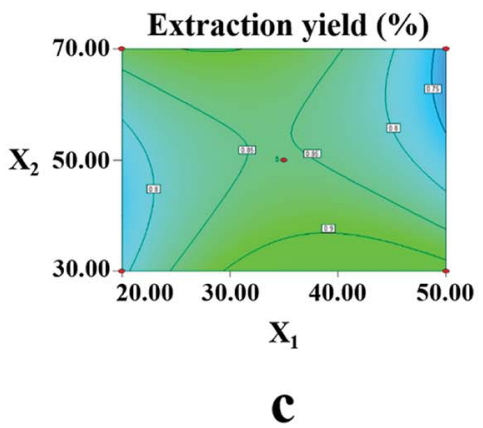

Fig. 5 Response surface (3-D) and contour plots showing the effects of ( $A$ and a) extraction temperature $\left(X_{2}\right)$ and ethanol concentration $\left(X_{3}\right)$, ( $B$ and b) ultrasonication time $\left(X_{1}\right)$ and ethanol concentration $\left(X_{3}\right)$ and $(C$ and $c)$ ultrasonication time $\left(X_{1}\right)$ and extraction temperature $\left(X_{2}\right)$ on the extraction yield of $L J\left(Y_{1}\right)$.

easily dissolved in highly concentrated ethanol solution. Therefore, to improve the solubility of the medium-polarity target compounds, a higher ethanol concentration was used to enhance the value of $Y_{1}$. Fig. 5B and b show the interactive effects between ethanol concentration and ultrasonication time while the temperature remains at 0 -level. The value of $Y_{1}$ remarkably improved with increasing ethanol concentration from $20 \%$ to $60 \%(\mathrm{v} / \mathrm{v})$, while $Y_{1}$ increased slightly with increasing ultrasonication time from 30 to $50 \mathrm{~min}$. The main reason for this may be saturation of the solution; as the time increased, most components were extracted completely. Fig. 5C and $\mathrm{c}$ show the interactive effects between the temperature and ultrasonication time while the ethanol concentration was fixed. The value of $Y_{1}$ increased remarkably with increasing temperature, while the changes in the ultrasonication time had almost no effect on $Y_{1}$ after $50 \mathrm{~min}$. The above results are in accordance with the ANOVA (Table 4 ). These results indicate that $X_{2}, X_{3}$ and $X_{2} X_{3}$ are significant $(p<0.05)$ for $Y_{1}$.

After optimization by the BBD software, the optimum conditions were an ultrasonication time of $41.2 \mathrm{~min}$, a temperature of $30.0{ }^{\circ} \mathrm{C}$, an ethanol concentration of $70.0 \%(\mathrm{v} / \mathrm{v})$, a solid-liquid ratio of $30.0 \mathrm{~mL} \mathrm{~g}^{-1}$ and an ultrasonic power of $500.0 \mathrm{~W}$.

3.3.2.2. TT assay $\left(Y_{2}\right)$. To explain the interactive effects on the anticoagulation activities of $\mathrm{LJ}$ extracts, three dimensional response surfaces are displayed in Fig. $6 \mathrm{~A}-\mathrm{C}$; the contour plots are shown in Fig. 6a-c. Fig. 6A and a show the interactive effects between ethanol concentration and temperature with a fixed ultrasonication time. $Y_{2}$ showed an enhancement and then decreased slightly when the ethanol concentration increased from $20 \%$ to $50 \%(\mathrm{v} / \mathrm{v})$ and the temperature increased from $30^{\circ} \mathrm{C}$ to $50^{\circ} \mathrm{C}$. Most of the components of LJ dissolved easily in highly concentrated ethanol solution. At the same time, with increasing temperature, the molecular movement became violent, resulting in complete extraction of the LJ. More extracted components may promote invigoration of the blood circulation. However, when the solution became saturated, the increases in ethanol concentration and temperature became unimportant. Fig. 6B and b show the interactive effects between ethanol concentration and ultrasonication time at a fixed temperature. As before, $Y_{2}$ improved remarkably when the ethanol concentration increased from $20 \%$ to $60 \%$. Fig. $6 \mathrm{C}$ and c show the interactive effects between the temperature and ultrasonication time with a stable ethanol concentration. $Y_{2}$ increased as the temperature increased from $30^{\circ} \mathrm{C}$ to $60{ }^{\circ} \mathrm{C}$. However, extension of the ultrasonication time did not greatly affect $Y_{2}$. The ANOVA results (Table 4) showed that $X_{1}$ and $X_{3}{ }^{2}$ were significant $(p<0.05)$ for $Y_{2}$ and that $X_{1}$ and $X_{3}$ are the major factors affecting $Y_{2}$. Therefore, for $Y_{2}$, the optimum conditions were found to be as follows: ultrasonication time, $20.0 \mathrm{~min}$; temperature, $70.0{ }^{\circ} \mathrm{C}$; ethanol concentration, $34.1 \%(\mathrm{v} / \mathrm{v})$; solidliquid ratio, $30.0 \mathrm{~mL} \mathrm{~g}^{-1}$; and ultrasonic power, $500.0 \mathrm{~W}$.

3.3.2.3. PT assay $\left(Y_{3}\right)$. The three-dimensional response surfaces and contour plots for $\mathrm{Y}_{3}$ are displayed in Fig. S5A-C and Fig. S5a-c, $\dagger$ respectively. Firstly, Fig. S5A and a $\uparrow$ show the interactive effects between ethanol concentration and temperature with a fixed ultrasonication time. When the ethanol concentration increased, $Y_{3}$ improved. Secondly, Fig. S5B and $\mathrm{b} \dagger$ show the interactive effects between ethanol concentration and ultrasonication time at a stable temperature. Obviously, $Y_{3}$ 


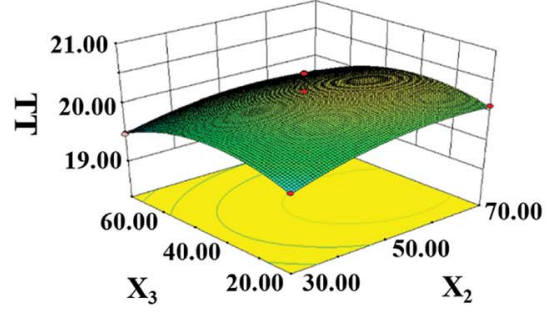

A

TT

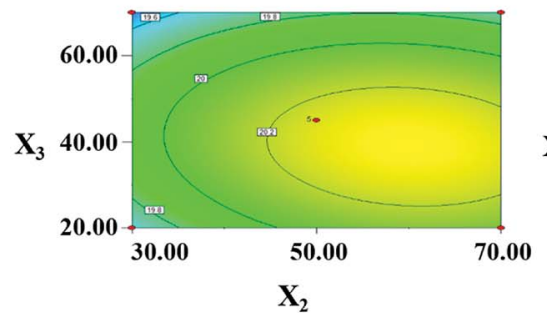

$\mathbf{a}$

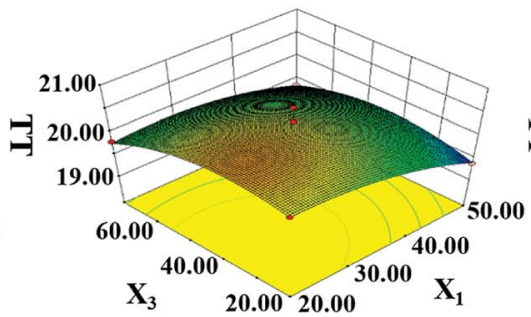

B

TT

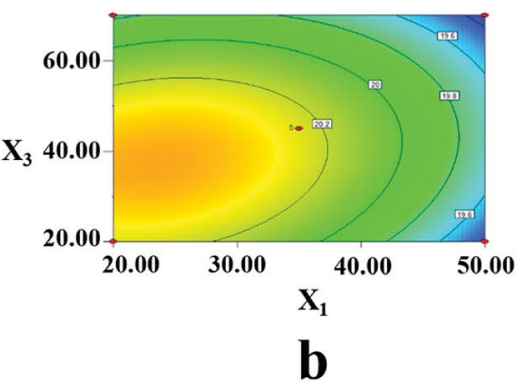

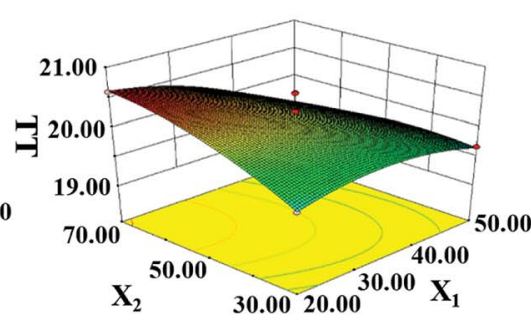

C

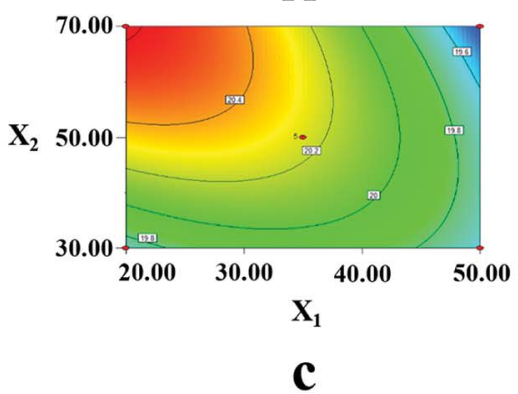

Fig. 6 Response surface (3-D) and contour plots showing the effects of ( $A$ and a) extraction temperature $\left(X_{2}\right)$ and ethanol concentration $\left(X_{3}\right)$, ( $B$ and b) ultrasonication time $\left(X_{1}\right)$ and ethanol concentration $\left(X_{3}\right)$ and $\left(C\right.$ and c) ultrasonication time $\left(X_{1}\right)$ and extraction temperature $\left(X_{2}\right)$ on TT $\left(Y_{2}\right)$.

was affected by the ethanol concentration. Finally, Fig. S5C and $c \dagger$ showed the interactive effects between the temperature and ultrasonication time at a fixed ethanol concentration. $Y_{3}$ decreased markedly with increasing temperature and ultrasonication time. The above results are in accordance with the ANOVA (Table 4), which showed that $X_{1} X_{2}, X_{1} X_{3}$ and $X_{2} X_{3}$ are significant $(p<0.05)$ for $Y_{3}$. For $Y_{3}$, the optimum conditions were found to be as follows: ultrasonication time, $20.0 \mathrm{~min}$; temperature, $70.0{ }^{\circ} \mathrm{C}$; ethanol concentration, $53.7 \%(\mathrm{v} / \mathrm{v})$; solidliquid ratio, $30.0 \mathrm{~mL} \mathrm{~g}^{-1}$; and ultrasonic power, $500.0 \mathrm{~W}$.

3.3.2.4. APTT assay ( $Y_{4}$ ). Fig. S6A-C and Fig. S6a-c† show how the ethanol concentration, temperature and ultrasonication affect the blood circulation invigoration activities of LJ extract. From the results, ethanol concentration plays the most important role of the three independent variables. $Y_{4}$ showed an obvious improvement with increasing ethanol concentration and showed no changes with increasing temperature and ultrasonication time. This analysis was in keeping with the ANOVA (Table 4), which showed that $X_{3}$ is the major factor affecting $Y_{4}$ and that $X_{1}^{2}$ and $X_{3}$ are significant $(p<$ 0.05 ) for $Y_{4}$. For $Y_{4}$, the optimum conditions were found to be as follows: ultrasonication time, $20.0 \mathrm{~min}$; temperature, $70.0{ }^{\circ} \mathrm{C}$; ethanol concentration, $70.0 \%(\mathrm{v} / \mathrm{v})$; solid-liquid ratio, $30.0 \mathrm{~mL}$ $\mathrm{g}^{-1}$; and ultrasonic power, $500.0 \mathrm{~W}$.

3.3.2.5. FIB assay $\left(Y_{5}\right) . Y_{5}$ is closely connected with the blood circulation invigorating activities of LJ extract. Next, Fig. S7A-C and Fig. S7a-c $\dagger$ show the relationships between the three independent variables and $Y_{5}$. Fig. S7A and a $\uparrow$ show the interactive effects of ethanol concentration and temperature with a fixed ultrasonication time. $Y_{5}$ decreased as the ethanol concentration increased. Fig. S7B and $\mathrm{b} \dagger$ show the interactive effects of ethanol concentration and ultrasonication time at a stable temperature. The ethanol concentration also affected $Y_{5}$ remarkably, while the ultrasonication time showed no effects. Fig. S7C and $c \dagger$ show the interactive effects of temperature and ultrasonication time at a constant ethanol concentration. $Y_{5}$ decreased with increasing temperature. The above results are in line with the ANOVA (Table 4), which indicates that $X_{1}{ }^{2}, X_{3}{ }^{2}$ and $X_{3}$ are significant $(p<0.05)$ for $Y_{5}$ and that $X_{3}$ is the major factor affecting $Y_{5}$. For $Y_{5}$, the optimum extraction parameters were found to be as follows: ultrasonication time of $38.3 \mathrm{~min}$, temperature of $30.1{ }^{\circ} \mathrm{C}$, ethanol concentration of $20.4 \%(\mathrm{v} / \mathrm{v})$, solid-liquid ratio of $30.0 \mathrm{~mL} \mathrm{~g}^{-1}$ and ultrasonic power of $500.0 \mathrm{~W}$.

3.3.2.6. $D P P H$ free radical scavenging activity $\left(Y_{6}\right)$. To investigate the interactive effects on the antioxidant activities of LJ extract, three dimensional response surface and contour plots were drawn and are displayed in Fig. S8A-C and Fig. S8a-c, $\dagger$ respectively. First, Fig. S8A and a $\dagger$ show that increasing the ethanol concentration led to a rapid decrease of $Y_{6}$ when the ultrasonication time was fixed. Fig. S8B and $\mathrm{b} \dagger$ show that $Y_{6}$ decreased with increasing ethanol concentration and ultrasonication time at the same time. Fig. S8C and c† show that when the ethanol concentration was stable, $Y_{6}$ changed slightly with increasing temperature and ultrasonication time. The above results are in keeping with the ANOVA (Table 4), which shows that $X_{3}$ and $X_{3}{ }^{2}$ are significant $(p<0.05)$ for $Y_{6}$ and that $X_{3}$ is the major factor affecting $Y_{6}$. Therefore, for $Y_{6}$, the optimum parameters were found to be as follows: ultrasonication time, $30.6 \mathrm{~min}$; temperature, $70.0{ }^{\circ} \mathrm{C}$; ethanol concentration, $48.1 \%$ $(\mathrm{v} / \mathrm{v})$; solid-liquid ratio, $30.0 \mathrm{~mL} \mathrm{~g}^{-1}$; and ultrasonic power, $500.0 \mathrm{~W}$. 
3.3.3. Validation of the predicted value. In consideration of the multiple indicators of this experiment model, it was difficult to consider all of them. Therefore, the function of Design Expert software version 8.0 called 'Numerical Optimization' was used to coordinate all the conditions. Then, we acquired the optimal ultrasonic extraction conditions according to the model equation by predicting the response values: ultrasonication time, $38.2 \mathrm{~min}$; temperature, $30.0{ }^{\circ} \mathrm{C}$; ethanol concentration, $48.9 \%$ $(\mathrm{v} / \mathrm{v})$; solid-liquid ratio, $30.0 \mathrm{~mL} \mathrm{~g}^{-1}$; and ultrasonic power, $500.0 \mathrm{~W}$. Under the optimal extraction conditions, the experimental values (extraction yield of $\mathrm{LJ}=0.994 \%$, TT $=19.872 \mathrm{~s}$, $\mathrm{PT}=8.270 \mathrm{~s}, \mathrm{APTT}=15.535 \mathrm{~s}, \mathrm{FIB}=1.420 \mathrm{~g} \mathrm{~L}^{-1}$ and DPPH $=$ $1.503 \mathrm{mg} \mathrm{mL}^{-1}$ ) were acquired was and were well matched with the predicted values (extraction yield of $\mathrm{LJ}=0.992 \%$, TT $=$ $19.876 \mathrm{~s}, \mathrm{PT}=8.249 \mathrm{~s}, \mathrm{APTT}=15.452 \mathrm{~s}, \mathrm{FIB}=1.420 \mathrm{~g} \mathrm{~L}^{-1}$ and $\mathrm{DPPH}=1.498 \mathrm{mg} \mathrm{mL}^{-1}$ ). The excellent correlations between the experimental and predicted values indicated that the model obtained by BBD can accurately predict the anticoagulant and antioxidant extraction yield of LJ using UAE.

\section{Conclusion}

In this study, UAE was successfully optimized for the maximum extraction of natural antioxidants and anticoagulants from $\mathrm{LJ}$ using BBD. Five impact factors of extraction (ethanol concentration, solid-liquid ratio, ultrasonication time, ultrasonic power and temperature) were evaluated, and the results indicated that ethanol concentration, ultrasonication time and temperature have significant effects on the yield of antioxidants and anticoagulants extracted from LJ. Furthermore, the optimal technology was determined to be an ultrasonication time of $38.2 \mathrm{~min}$; a temperature of $30.0^{\circ} \mathrm{C}$; an ethanol concentration of $48.9 \%(\mathrm{v} / \mathrm{v})$; a solid-liquid ratio of $30.0 \mathrm{~mL} \mathrm{~g}^{-1}$; and an ultrasonic power of $500.0 \mathrm{~W}$. These results demonstrate that UAE coupled with RSM is an effectual and feasible method for the extraction of natural antioxidants and anticoagulants from LJ; this will provide a scientific basis for the comprehensive utilization and development of LJ.

\section{Conflicts of interest}

There are no conflicts to declare.

\section{Acknowledgements}

This work was financially supported by the National Standardization Project for Traditional Chinese Medicines (ZYBZH-C-JS34), National Natural Science Foundation of China (81573714, 81603257, 81773882, 81781260279 and 81803699) and 333 High-level Talents Training Project Funded by Jiangsu Province (BRA2016387). This research was also financially supported by Jiangsu Collaborative Innovation Center of Chinese Medicinal Resources Industrialization (No. 012092002006-4), A Project Funded by the Priority Academic Program Development of Jiangsu Higher Education Institutions (PAPD) and China Agriculture Research System (CARS-21). We are also pleased to thank Waters Ltd. for technical support.

\section{References}

1 X. Shang, H. Pan, X. Wang, H. He and M. Li, J. Ethnopharmacol., 2014, 152, 14-32.

2 A. S. Oliveira, L. M. Cercato, M. T. de Santana Souz, A. J. de Oliveira Melo, B. d. S. Lima, M. C. Duarte, A. A. de Souza Araujo, A. M. de Oliveira e Silva and E. A. Camargo, J. Ethnopharmacol., 2017, 206, 144-151.

3 H. Nagasawa, H. Inatomi, M. Suzuki and T. Mori, Anticancer Res., 1992, 12, 141-143.

4 H. Q. Pang, S. J. Yue, Y. P. Tang, Y. Y. Chen, Y. J. Tan, Y. J. Cao, X. Q. Shi, G. S. Zhou, A. Kang, S. L. Huang, Y. J. Shi, J. Sun, Z. S. Tang and J. A. Duan, Front. Pharmacol., 2018, 9, 1-18.

5 S. W. Park, R. Vepachedu, N. Sharma and J. M. Vivanco, Planta, 2004, 219, 1093-1096.

6 C. Kaur and H. C. Kapoor, Int. J. Food Sci. Technol., 2001, 36, 703-725.

7 A. Kumar and A. Singh, Front. Pharmacol., 2015, 6, 1-13.

8 I. S. Young and J. V. Woodside, J. Clin. Pathol., 2001, 54, 176186.

9 A. W. Boots, G. R. M. M. Haenen and A. Bast, Eur. J. Pharmacol., 2008, 585, 325-337.

10 S. Li, H. Y. Tan, N. Wang, Z. J. Zhang, L. Lao, C. W. Wong and Y. Feng, Int. J. Mol. Sci., 2015, 16, 26087-26124.

11 F. M. F. Roleira, E. J. Tavares-da-Silva, C. L. Varela, S. C. Costa, T. Silva, J. Garrido and F. Borges, Food Chem., 2015, 183, 235-258.

12 G. F. Deng, C. Shen, X. R. Xu, R. D. Kuang, Y. J. Guo, L. S. Zeng, L. L. Gao, X. Lin, J. F. Xie, E. Q. Xia, S. Li, S. Wu, F. Chen, W. H. Ling and H. B. Li, Int. J. Mol. Sci., 2012, 13, 8308-8323.

13 M. E. Embuscado, J. Funct. Foods, 2015, 18, 811-819.

14 E. N. Frankel and J. W. Finley, J. Agric. Food Chem., 2008, 56, 4901-4908.

15 P. V. Hung, Crit. Rev. Food Sci. Nutr., 2016, 56, 25-35.

16 S. Li, S. K. Li, R. Y. Gan, F. L. Song, L. Kuang and H. B. Li, Ind. Crops Prod., 2013, 51, 289-298.

17 F. Shahidi and P. Ambigaipalan, J. Funct. Foods, 2015, 18, 820-897.

18 B. Gullon, T. A. Lu-Chau, M. T. Moreira, J. M. Lema and G. Eibes, Trends Food Sci. Technol., 2017, 67, 220-235.

19 M. Arshadi, T. M. Attard, R. M. Lukasik, M. Brncic, A. M. d. C. Lopes, M. Finell, P. Geladi, L. Noemi Gerschenson, F. Gogus, M. Herrero, A. J. Hunt, E. Ibanez, B. Kamm, I. Mateos-Aparicio, A. Matias, N. E. Mavroudis, E. Montoneri, A. R. C. Morais, C. Nilsson, E. H. Papaioannou, A. Richel, P. Ruperez, B. Skrbic, M. B. Solarov, J. Svarc-Gajic, K. W. Waldron and F. J. YusteCordoba, Green Chem., 2016, 18, 6160-6204.

20 F. Dahmoune, H. Remini, S. Dairi, O. Aoun, K. Moussi, N. Bouaoudia-Madi, N. Adjeroud, N. Kadri, K. Lefsih, L. Boughani, L. Mouni, B. Nayak and K. Madani, Ind. Crops Prod., 2015, 77, 251-261.

21 L. Liu, B. J. Shen, D. H. Xie, B. C. Cai, K. M. Qin and H. Cai, Pharmacogn. Mag., 2015, 11, 682-689. 
22 F. Dahmoune, B. Nayak, K. Moussi, H. Remini and K. Madani, Food Chem., 2015, 166, 585-595.

23 D. Povilaitis, V. Sulniute, P. R. Venskutonis and V. Kraujaliene, J. Cereal Sci., 2015, 62, 117-123.

24 B. Diaz-Reinoso, A. Moure, H. Dominguez and J. C. Parajo, J. Agric. Food Chem., 2006, 54, 2441-2469.

25 Z. Zeković, A. Cvetanović, J. Švarc-Gajić, S. Gorjanović, D. Sužnjević, P. Mašković, S. Savić, M. Radojković and S. Đurović, Ind. Crops Prod., 2017, 108, 423-430.

26 P. Mašković, V. Veličković, M. Mitić, S. Đurović, Z. Zeković, M. Radojković, A. Cvetanović, J. Švarc-Gajić and J. Vujić, Ind. Crops Prod., 2017, 109, 875-881.

27 P. Mašković, V. Veličković, S. Đurović, Z. Zeković, M. Radojković, A. Cvetanović, J. Švarc-Gajić, M. Mitić and J. Vujić, Phytomedicine, 2017, 38, 118-124.

28 V. Veličković, S. Đurović, M. Radojković, A. Cvetanović, J. Švarc-Gajić, J. Vujić, S. Trifunović and P. Mašković, J. Supercrit. Fluids, 2017, 128, 331-337.

29 E. Backes, C. Pereira, L. Barros, M. A. Prieto, A. K. Genena, M. F. Barreiro, et al., Food Res. Int., 2018, 113, 197-209.

30 M. D. Esclapez, J. V. Garcia-Perez, A. Mulet and J. A. Carcel, Food Eng. Rev., 2011, 3, 108-120.

31 O. Laguna, A. Barakat, H. Alhamada, E. Durand, B. Barea, F. Fine, P. Villeneuve, M. Citeau, S. Dauguet and J. Lecomte, Ind. Crops Prod., 2018, 118, 160-172.

32 T. Zhang, A. Sharma, Y. Li, Y. Zhou and X. Ding, J. Photochem. Photobiol., A, 2018, 178, 568-576.

33 C. Li, H. Song, Y. Jiao and H. Gao, Sci. Technol. Food Ind., 2016, 37, 204-209.

34 I. Rodriguez Amado, D. Franco, M. Sanchez, C. Zapata and J. Antonio Vazquez, Food Chem., 2014, 165, 290-299.
35 S. Y. Yang, S. W. Kim, Y. Kim, S. H. Lee, H. Jeon and K. W. Lee, Food Chem., 2015, 176, 420-425.

36 M. Pei, X. Duan and X. Pei, China J. Chin. Mater. Med., 2009, 34, 2047-2050.

37 X. Cheng, X. Sang, Q. Yang, J. Meng, X. Tang and C. Zhang, Chin. J. Hosp. Pharm., 2013, 33, 1850-1852.

38 B. Liu and Y. Chen, J. Shenyang Pharm. Univ., 2016, 33, 303306.

39 C. Zhou, Y. Zhang, Y. He, Y. Wang, J. Yu, Z. Dai and S. Ma, Chin. J. Pharm. Anal., 2016, 36, 830-834.

40 S. Tahmouzi and M. Ghodsi, Carbohydr. Polym., 2014, 112, 396-403.

41 Z. Yin, W. Zhang, J. Zhang and W. Kang, Chem. Cent. J., 2017, 11, 1-10.

42 A. S. Ahmed, E. E. Elgorashi, N. Moodley, L. J. McGaw, V. Naidoo and J. N. Eloff, J. Ethnopharmacol., 2012, 143, 826-839.

43 A. Pandey, T. Belwal, K. C. Sekar, I. D. Bhatt and R. S. Rawal, Ind. Crops Prod., 2018, 119, 218-225.

44 K. H. Wong, G. Q. Li, K. M. Li, V. Razmovski-Naumovski and K. Chan, Food Chem., 2017, 231, 231-237.

45 D. P. Xu, J. Zheng, Y. Zhou, Y. Li, S. Li and H.-B. Li, Food Chem., 2017, 217, 552-559.

46 S. Chen, Z. Zeng, N. Hu, B. Bai, H. Wang and Y. Suo, Food Chem., 2018, 242, 1-8.

47 A. B. Das, V. V. Goud and C. Das, Ind. Crops Prod., 2017, 95, 332-341.

48 X. Guo, X. Shang, X. Zhou, B. Zhao and J. Zhang, Ultrason. Sonochem., 2017, 38, 246-255.

49 H. Zhang, J. Birch, C. Xie, H. Yang, G. Dias, L. Kong and A. E. D. Bekhit, Ind. Crops Prod., 2018, 119, 191-200. 